\title{
ENDOTRACHEAL INTUBATION USING PROPOFOL, MIDAZOLAM, LIGNOCAINE INDUCTION ALONG WITH FENTANYL IN TWO DIFFERENT DOSES; WITHOUT USING NEUROMUSCULAR BLOCKING DRUGS: A COMPARATIVE RANDOMISED PROSPECTIVE STUDY
}

Bhanuprakash S1, Sudhir Kumar P2, Sahajananda H³, Sowmya M. J4, Venkatesh Murthy K. T5

\section{HOW TO CITE THIS ARTICLE:}

Bhanuprakash S, Sudhir Kumar P, Sahajananda H, Sowmya M. J, Venkatesh Murthy K. T. "Endotracheal Intubation Using Propofol, Midazolam, Lignocaine Induction along with Fentanyl in Two Different Doses; without Using Neuromuscular Blocking Drugs: A Comparative Randomised Prospective Study". Journal of Evolution of Medical and Dental Sciences 2015; Vol. 4, Issue 58, July 20; Page: 10039-10048,

DOI: $10.14260 /$ jemds/2015/1453

ABSTRACT: BACKGROUND: The standard techniques of tracheal intubation are usually done after induction of anaesthesia followed by skeletal muscle relaxation. The muscle relaxants are associated with many side effects. These side effects have spurred research into development of alternative methods for providing good intubating conditions. AIMS AND OBJECTIVES: Present study is designed to compare the intubating conditions, hemodynamic changes following two different doses of fentanyl ( 2 and $3 \mathrm{mcg} / \mathrm{kg}$ ) using midazolam, lignocaine and propofol induction. MATERIALS AND METHOD: A prospective randomized study was carried out in the department of Anaesthesia at Rajarajeswari Medical College and Hospital. The patients of either sex and age group between 18 and 60years belonging to ASA I and II scheduled for operation under general anaesthesia in various surgical departments for elective surgery were subjects of our study. Patients were randomly divided into two groups of 50 patients each. Group-I received Midazolam $(0.04 \mathrm{mg} / \mathrm{kg})$, study drug Fentanyl $(2 \mathrm{mcg} / \mathrm{kg})$, Lignocaine $(1.5 \mathrm{mg} / \mathrm{kg})$ and propofol $(2 \mathrm{mg} / \mathrm{kg})$. Group-II received Midazolam $(0.04 \mathrm{mg} / \mathrm{kg})$, study drug Fentanyl $(3 \mathrm{mcg} / \mathrm{kg})$, Lignocaine $(1.5 \mathrm{mg} / \mathrm{kg})$ and propofol $(2 \mathrm{mg} / \mathrm{kg})$. STATISTICAL ANALYSIS: To assess the intubating conditions Statistical test used was chi square test and software used was SPSS version 10. The power we achieved for response to intubation is 0.95 . To assess the hemodynamic effects Statistical test used was paired $t$ test within the group and student $t$ test between the groups and software used was SPSS version 10. The power we achieved for pulse rate and mean BP is 0.81 and 0.93 respectively. RESULTS AND CONCLUSION: showed that fentanyl $3 \mathrm{mcg} / \mathrm{kg}$ with propofol, midazolam and lignocaine provides better intubating conditions and effective in blunting hemodynamic responses to intubation when compared to fentanyl $2 \mathrm{mcg} / \mathrm{kg}$. Fentanyl $3 \mathrm{mcg} / \mathrm{kg}$ with propofol, midazolam and lignocaine combination represents a useful alternative technique for tracheal intubation when neuromuscular blocking drugs are contraindicated or should be avoided.

KEYWORDS: Intubating conditions, Fentanyl (2 \& 3mcg/kg), Propofol.

INTRODUCTION: Endotracheal intubation is of paramount importance in practice of general anaesthesia. The ease with which endotracheal intubation is achieved depends on technical proficiency, depth of anaesthesia and degree of muscular relaxation. The interplay of these three factors is such that a deficiency of one or two of them can be compensated for by the remaining factors.

Intubation in anaesthesia using short-acting hypnotic drugs is frequently facilitated by the simultaneous administration of a depolarising muscle relaxant such as succinylcholine. However, 


\section{ORIGINAL ARTICLE}

succinylcholine administration may be associated, at times, with side effects such as prolonged paralysis, postoperative myalgia, malignant hyperthermia, hyperkalemia, or increase in intracranial or intraocular pressure. These side effects have spurred research into the development of a nondepolarizing drug with short onset of action.

However, even the use of non-depolarizing relaxants may be associated with undesirable effects such as prolonged neuromuscular blockade, the need to reverse neuromuscular blockade or the inability to reverse the paralysis quickly if airway management via mask or tracheal intubation is not possible. Induction with inhalational agents is also associated with lack of smoothness, delay and inadequate muscle relaxation.

The purpose of the present study was to evaluate intubating conditions and hemodynamic responses in healthy adult patients with favorable airway anatomy by doing intravenous induction of anaesthesia with midazolam, fentanyl, lignocaine and propofol without use of neuromuscular blocking agents. Two doses of fentanyl $2 \mathrm{mcg} / \mathrm{kg} \mathrm{\&} 3 \mathrm{mcg} / \mathrm{kg}$ were compared.

MATERIAL AND METHODS: After approval from the institutional ethical committee and a written informed consent, this comparative study was carried out on 100 patients, ASA Grade I \& II and MP Grade I undergoing surgeries under general anaesthesia were selected. Exclusion criteria included the history of intravenous drug use, alcohol addiction, full stomach, coronary artery disease, obstetric or gastroesophageal reflux disease. Informed consent was taken for study and patients were randomly divided into two groups of 50 patients each and all the patients were premedicated with glycopyrrolate $0.2 \mathrm{mg}$ IV.

Group I: Received Midazolam (0.04mg/kg), study drug Fentanyl (2mcg/kg), Lignocaine (1.5mg/kg) and propofol $(2 \mathrm{mg} / \mathrm{kg})$.

Group II: Received Midazolam $(0.04 \mathrm{mg} / \mathrm{kg})$, study drug Fentanyl (3mcg/kg), Lignocaine $(1.5 \mathrm{mg} / \mathrm{kg})$ and propofol $(2 \mathrm{mg} / \mathrm{kg})$.

To randomly select the study group (I or II) and to make the study group blind, assistant's help was taken. Helping assistant prepared the study drug fentanyl $(2 \mathrm{mcg} / \mathrm{kg}$ or $3 \mathrm{mcg} / \mathrm{kg}$ ) relevant to the study group in $5 \mathrm{ml}$ volume, as per lottery result, this was made to eliminate the observer bias. The above mentioned drugs in both the groups were administered at a given time interval as in (FIGURE-1).

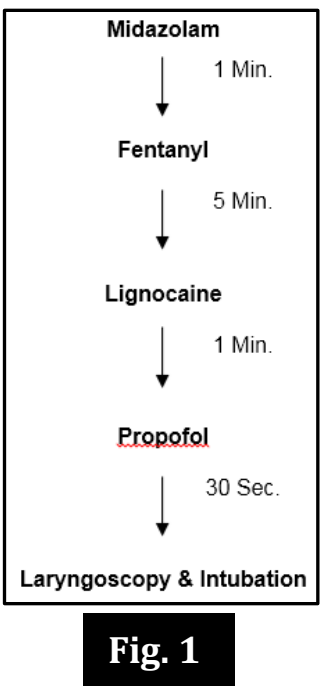




\section{ORIGINAL ARTICLE}

During and within $1 \mathrm{~min}$ of laryngoscopy and intubation, the intubating anesthesiologist assessed each patient for five variables using MARK S. SCHELLER scoring criteria for various airway conditions (TABLE-1).

\begin{tabular}{|c|c|}
\hline Criteria & Score \\
\hline \multicolumn{2}{|l|}{ Jaw Relaxation } \\
\hline Jaw freely mobile \& relaxed & 1 \\
\hline Jaw partially mobile & 2 \\
\hline Jaw Immobile & 3 \\
\hline \multicolumn{2}{|l|}{ Mask Ventilation } \\
\hline Mask ventilation easy & 1 \\
\hline Mask ventilation difficult & 2 \\
\hline Mask ventilation impossible & 3 \\
\hline \multicolumn{2}{|l|}{ Exposure of Vocal cords } \\
\hline $\begin{array}{l}\text { Vocal cords and arytenoids completely } \\
\text { visible }\end{array}$ & 1 \\
\hline Vocal cords and arytenoids partly visible & 2 \\
\hline Vocal cords and arytenoids not visible & 3 \\
\hline \multicolumn{2}{|l|}{ Position of Vocal cords } \\
\hline Vocal cords open & 1 \\
\hline Vocal cords mid position & 2 \\
\hline Vocal cords closed & 3 \\
\hline \multicolumn{2}{|l|}{ Cough/Movements after intubation } \\
\hline No movements & 1 \\
\hline One or two coughs & 2 \\
\hline Persistent coughing & 3 \\
\hline Purposeful movements & 4 \\
\hline \multicolumn{2}{|c|}{ Tracheal intubation without additional drugs given } \\
\hline Yes & \\
\hline No & \\
\hline $\begin{array}{l}\text { The Scoring for Various Airway } \\
\text { Conditions (Marks. Scheller) }\end{array}$ & \\
\hline
\end{tabular}

- Jaw relaxation.

- Mask ventilation.

- Exposure of vocal cords.

- Comparison of Position of vocal cords.

- Cough/movements after intubation.

In case where intubation was not possible, Succinylcholine $2 \mathrm{mg} / \mathrm{kg}$ was given to facilitate laryngoscopy and intubation.

Vital signs like pulse rate, BP were recorded prior to induction, post induction and once the patient was intubated at 1, 2, 5, 10, 15 and 30 minutes and side effects were noted. 


\section{ORIGINAL ARTICLE}

\section{STATISTICAL ANALYSIS:}

- To assess the intubating conditions Statistical test used was chi square test and software used was SPSS version 10. The power we achieved for response to intubation is 0.95 .

- To assess the hemodynamic effects Statistical test used was paired t test within the group and student $t$ test between the groups and software used was SPSS version 10. The power we achieved for pulse rate and mean BP is 0.81 and 0.93 respectively.

RESULTS: There were no significant differences between the groups in terms of gender distribution mean patient weight and mean patient age.

\section{COMPARISION OF INTUBATING CONDITIONS:}

- Mask ventilation was easy in all the patients among both the groups.

- Jaw mobility was significantly better ( $\mathrm{P}=0.04)$ in group II (Fentanyl $3 \mathrm{mcg} / \mathrm{kg})$, that is fully mobile in 47/50 (94\%) patients when compared to Group I (Fentanyl $2 \mathrm{mcg} / \mathrm{kg}$ ) it was found in $40 / 50(80 \%)$ patients (TABLE-2).

\begin{tabular}{|c|c|c|c|c|}
\hline \multirow[t]{2}{*}{$\begin{array}{l}\text { Criteria and score } \\
\text { (Jaw mobility) }\end{array}$} & \multicolumn{2}{|c|}{$\begin{array}{c}\text { Group I } \\
\text { (Fentanyl } 2 \mathrm{mcg} / \mathrm{kg} \text { ) } \\
\text { Out of } 50 \text { no. of patients }\end{array}$} & \multicolumn{2}{|c|}{$\begin{array}{c}\text { Group II } \\
\text { (Fentanyl } 3 \mathrm{mcg} / \mathrm{kg} \text { ) } \\
\text { Out of } 50 \text { no. of patients }\end{array}$} \\
\hline & No. & $\%$ & No. & $\%$ \\
\hline Mobile (1) & 40 & 80 & 47 & 94 \\
\hline Partially Mobile (2) & 10 & 20 & 3 & 6 \\
\hline Immobile (3) & 0 & 0 & 0 & 0 \\
\hline
\end{tabular}

- Vocal cords visibility was significantly better ( $\mathrm{P}=0.03$ ) in group II (Fentanyl $3 \mathrm{mcg} / \mathrm{kg}$ ), that is completely visible in 46/50 (92\%) patients when compared to Group I (Fentanyl $2 \mathrm{mcg} / \mathrm{kg}$ ) it was found in $37 / 50(74 \%)$ patients (TABLE-3).

\begin{tabular}{|l|c|c|c|c|}
\hline $\begin{array}{c}\text { Criteria and score } \\
\text { (Exposure of vocal cords) }\end{array}$ & $\begin{array}{c}\text { Group I } \\
\text { (Fentanyl 2 mcg/kg) } \\
\text { Out of 50 no. of patients }\end{array}$ & $\begin{array}{c}\text { Group II } \\
\text { (Fentanyl 3 mcg/kg) } \\
\text { Out of 50 no. of patients }\end{array}$ \\
\cline { 2 - 5 } & No. & $\mathbf{\%}$ & No. & \% \\
\hline Completely visible (1) & 37 & 74 & 46 & 92 \\
\hline Partially visible (2) & 12 & 24 & 4 & 8 \\
\hline Not visible (3) Comparison of Exposure of Vocal Cords \\
\hline \multicolumn{4}{|r}{} \\
\hline
\end{tabular}

- Vocal cords position was significantly better $(\mathrm{P}=0.01)$ in group II (Fentanyl $3 \mathrm{mcg} / \mathrm{kg}$ ), that is widely open in $46 / 50$ (92\%) patients when compared to group I (Fentanyl $2 \mathrm{mcg} / \mathrm{kg}$ ) it was found in 34/49 (69.38\%) patients (TABLE-4). 


\section{ORIGINAL ARTICLE}

\begin{tabular}{|c|c|c|c|c|}
\hline \multirow{2}{*}{$\begin{array}{c}\text { Criteria and score } \\
\text { (Position of vocal cords) }\end{array}$} & \multicolumn{2}{|c|}{$\begin{array}{c}\text { Group I } \\
\text { (Fentanyl 2 mcg/kg) } \\
\text { Out of 49 no. of patients }\end{array}$} & $\begin{array}{c}\text { Group II } \\
\text { (Fentanyl 3 mcg/kg) } \\
\text { Out of 50 no. of patients }\end{array}$ \\
\cline { 2 - 5 } & No. & $\mathbf{\%}$ & No. & \% \\
\hline Open (1) & 34 & 69.38 & 46 & 92 \\
\hline Mid Position (2) & 13 & 26.53 & 4 & 8 \\
\hline Closed (3) & 2 & 4.06 & 0 & 0 \\
\hline \multicolumn{2}{r}{ Comparison of Position Vocal Cords } \\
\end{tabular}

- Response to intubation was significantly better ( $\mathrm{P}=0.002)$ in group II (Fentanyl $3 \mathrm{mcg} / \mathrm{kg}$ ), that is absence of cough/ movements after intubation in 41/50 (82\%) patients when compared to group I (Fentanyl 2mcg/kg) it was found in 22/47 (46.80\%) patients (TABLE-5).

\begin{tabular}{|c|c|c|c|c|}
\hline \multirow{2}{*}{$\begin{array}{c}\text { Criteria and score } \\
\text { (Cough/movements } \\
\text { after intubation) }\end{array}$} & $\begin{array}{c}\text { Group I } \\
\text { (Fentanyl 2 mcg/kg) } \\
\text { Out of 47 no. of patients }\end{array}$ & $\begin{array}{c}\text { Group II } \\
\text { (Fentanyl 3 mcg/kg) } \\
\text { Out of 50 no. of patients }\end{array}$ \\
\cline { 2 - 5 } & No. & \% & No. & \% \\
\hline No cough/movements (1) & 22 & 46.80 & 41 & 82 \\
\hline One or two cough (2) & 17 & 36.12 & 7 & 14 \\
\hline Persistent cough (3) & 7 & 14.89 & 2 & 4 \\
\hline Purposeful movements (4) & 1 & 2.12 & 0 & 0 \\
\hline INTUBATION WITH ADDITIONAL & \multicolumn{3}{|c|}{3} & \multicolumn{2}{|c}{0} \\
DRUG (SUCCINYL CHOLINE) GIVEN & \multicolumn{3}{|c|}{} \\
\hline
\end{tabular}

We were not able to intubate in 3 patients in Group I, because in 1 patient vocal cords were not visible and in 2 patients vocal cords were closed and then intubation was achieved after administering succinyl choline at $2 \mathrm{mg} / \mathrm{kg}$ dose.

\section{COMPARISION OF HEMODYNAMIC VARIABLES:}

- PULSE RATE: (FIGURE-2).

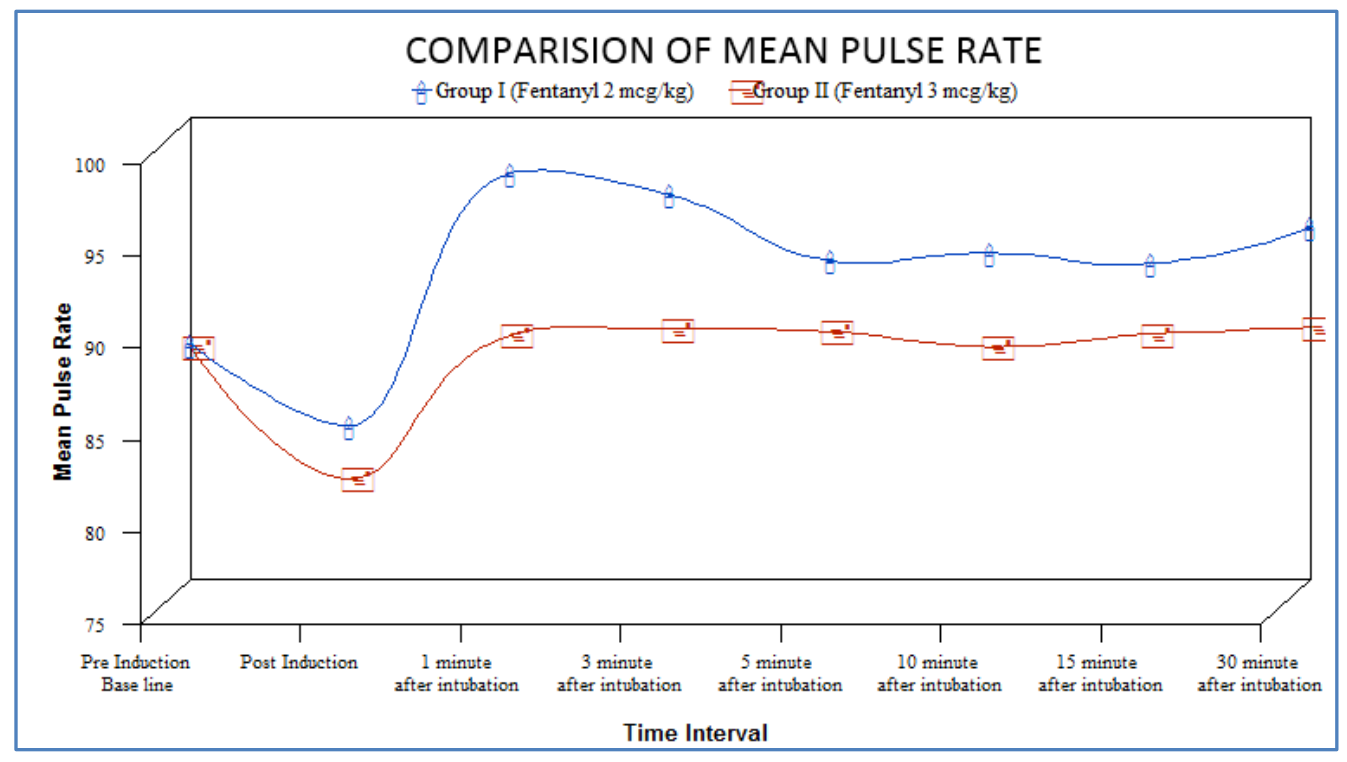




\section{ORIGINAL ARTICLE}

In group I (Fentanyl 2mcg/kg), 1 minute after intubation pulse rate was increased to 96.98 bpm (increase was $9.28 \mathrm{bpm}$ from the base line pulse rate $87.70 \mathrm{bpm}$ ), this increase in pulse rate was statistically highly significant $(\mathrm{P}=0.001)$. At 3 minutes pulse rate was $95.79 \mathrm{bpm}$ and at $5 \mathrm{~min}$ it was 92.26bpm. In group II (Fentanyl $3 \mathrm{mcg} / \mathrm{kg}$ ), $1 \mathrm{~min}$ after intubation pulse rate was increased to $88.20 \mathrm{bpm}$ (Increase was $0.6 \mathrm{bpm}$ from the base line pulse rate $87.60 \mathrm{bpm}$ ) this increase in pulse rate was statistically insignificant $(\mathrm{P}=0.79$ ). At 3 minutes it was $88.54 \mathrm{bpm}$ and at $5 \mathrm{~min}$ it was $92.26 \mathrm{bpm}$.

SYSTOLIC BP (SBP): (FIGURE-3):

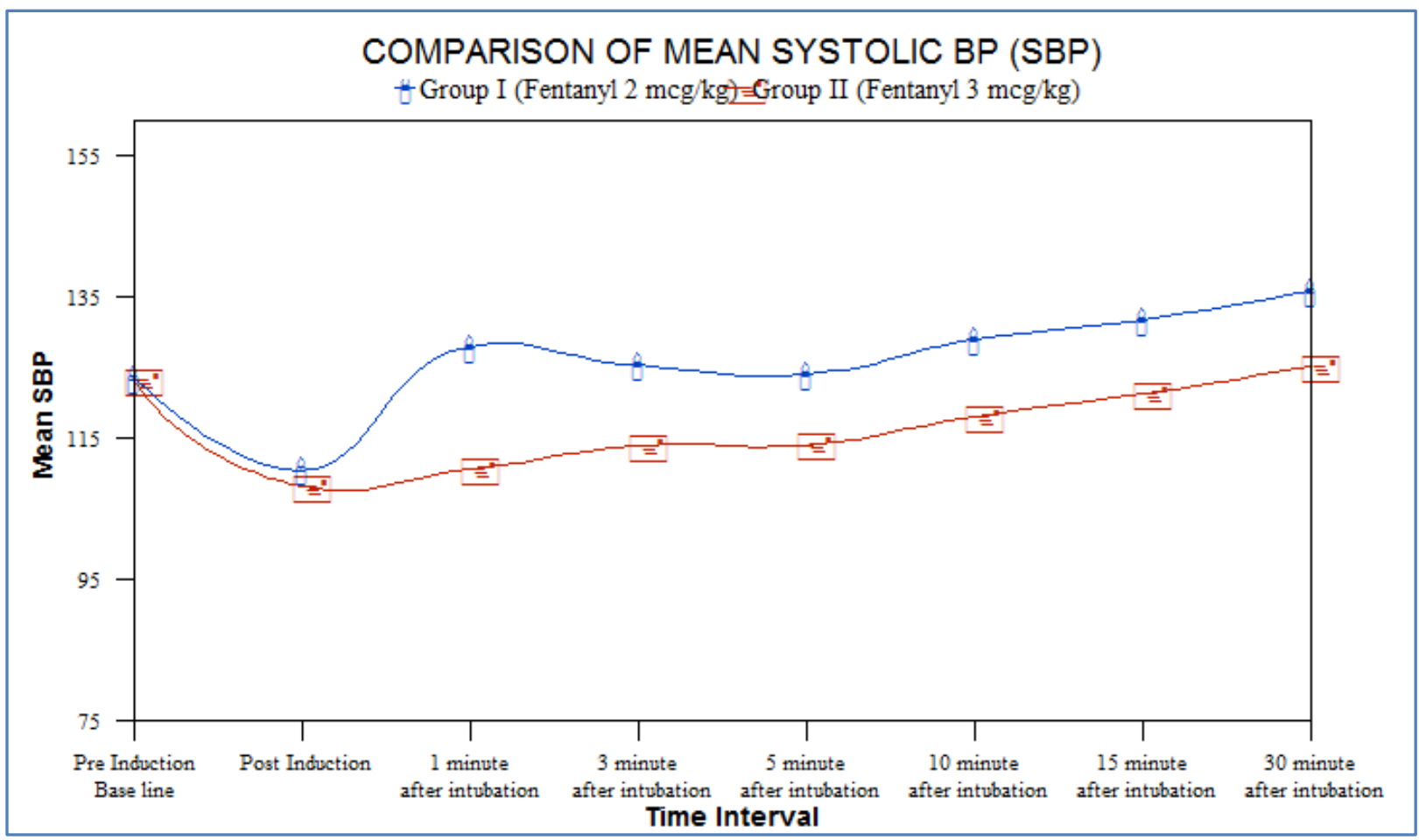

In group I: (Fentanyl $2 \mathrm{mcg} / \mathrm{kg}$ ), 1 minute after intubation SBP was increased to $128.00 \mathrm{~mm} \mathrm{Hg}$ (Increase was $4.36 \mathrm{~mm} \mathrm{Hg}$ from base line SBP $123.64 \mathrm{~mm} \mathrm{Hg}$ ) this increase was statistically insignificant $(\mathrm{P}=0.15)$. At 3 minutes it was $125.32 \mathrm{~mm} \mathrm{Hg}$, and at 5 minutes it was $124.15 \mathrm{~mm} \mathrm{Hg}$.

In group II: (Fentanyl 3mcg/kg), At 1 minute after intubation the decreased SBP after induction was maintained without significant change, it was $110.58 \mathrm{~mm} \mathrm{Hg}$ (But the decrease was $12.66 \mathrm{~mm} \mathrm{Hg}$ from the base line SBP $123.24 \mathrm{~mm} \mathrm{Hg}$ ). This decrease was statistically highly significant. At 3minutes it was $113.92 \mathrm{~mm} \mathrm{Hg}$ and at $5 \mathrm{minutes}$ it was $114.06 \mathrm{~mm} \mathrm{Hg}$. 


\section{ORIGINAL ARTICLE}

- (FIGURE-4): DIASTOLIC BP (DBP): Total number of patients 50 in each group.

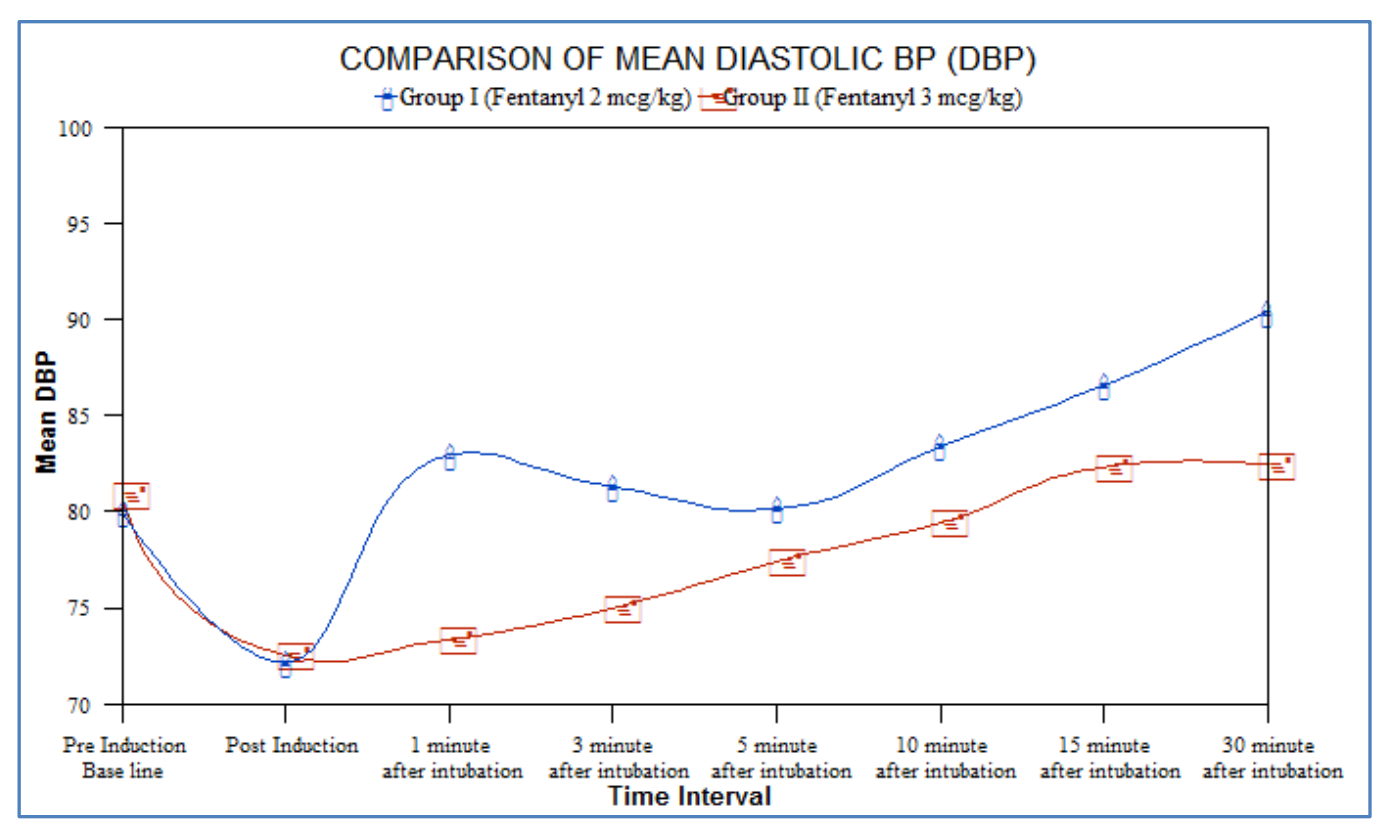

In group I (Fentanyl $2 \mathrm{mcg} / \mathrm{kg}$ ), 1 minute after intubations DBP was increased to $82.94 \mathrm{~mm} \mathrm{Hg}$ (increase was $2.99 \mathrm{~mm} \mathrm{Hg}$ from base line DBP $79.95 \mathrm{~mm} \mathrm{Hg}$ ) this increase was statistically not significant $(\mathrm{P}=0.29)$. At 3 minutes it was $81.28 \mathrm{~mm} \mathrm{Hg}$, and at $5 \mathrm{~min}$.

In group II (Fentanyl $3 \mathrm{mcg} / \mathrm{kg}$ ), At 1 minute after intubations the decreased DBP after induction was maintained without significant change, it was $73.36 \mathrm{~mm} \mathrm{Hg}$ (but the decrease was $7.48 \mathrm{~mm} \mathrm{Hg}$ from the base line DBP $80.84 \mathrm{~mm} \mathrm{Hg}$ ) This decrease was statistically highly significant $(\mathrm{P}=0.001)$. At 3 minutes it was $74.98 \mathrm{~mm} \mathrm{Hg}$ and at 5 minutes it was $77.40 \mathrm{~mm} \mathrm{Hg}$.

- (FIGURE-5): MEAN BP (MBP): Total number of patients 50 in each group

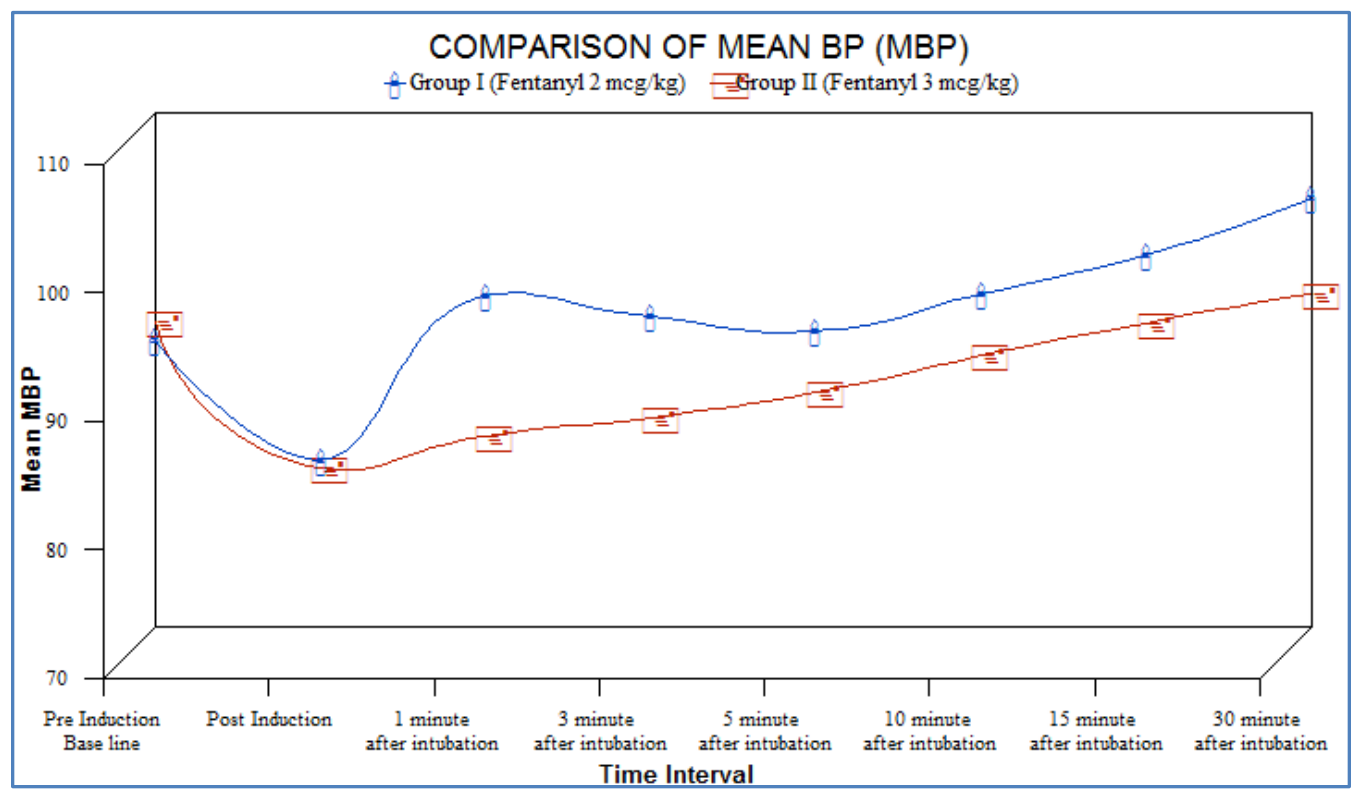


In group I (Fentanyl 2mcg/kg), 1minute after intubations MBP was increased to $95.74 \mathrm{~mm} \mathrm{Hg}$ (Increase was $3.51 \mathrm{~mm} \mathrm{Hg}$ from base line MBP $92.23 \mathrm{~mm} \mathrm{Hg}$ ) this increase was statistically not significant $(\mathrm{P}=0.23)$. At 3 minutes it was $94.11 \mathrm{~mm} \mathrm{Hg}$, and at $5 \mathrm{~min}$ it was $93.02 \mathrm{~mm} \mathrm{Hg}$.

In group II (Fentanyl $3 \mathrm{mcg} / \mathrm{kg}$ ), At 1 minute after intubations it decreased to $84.86 \mathrm{~mm} \mathrm{Hg}$ (Decrease was $8.86 \mathrm{~mm} \mathrm{Hg}$ from the base line MBP $93.72 \mathrm{~mm} \mathrm{Hg}$ ) This decrease in MBP was statistically significant $(\mathrm{P}=0.001)$. At 3 minutes it was $86.27 \mathrm{~mm} \mathrm{Hg}$ and at 5 minutes it was $88.26 \mathrm{~mm} \mathrm{Hg}$.

SIDE EFFECT: From the observation it was found that there was more incidence of Hypertension (28\%) \& Tachycardia (32\%) in Group I (Fentanyl 2mcg/kg) when compared to Group II (Fentanyl 3 $\mathrm{mcg} / \mathrm{kg}$ ) Hypertension (8\%) \& Tachycardia (12\%).

DISCUSSION: The present study was undertaken to evaluate the ease of performing laryngoscopy and endotracheal intubation without the use of muscle relaxant and to compare the intubating conditions, hemodynamic stability provided by two different doses of fentanyl ( 2 \& $3 \mathrm{mcg} / \mathrm{kg}$ ) among 100 patients and 50 patients in each group.

Time Sequence of Drugs given: (FIGURE-1): Drug administration plan was decided so that peak effect of each drugs coincides with the time of intubation. All the patients were given glycopyrrolate as premedication.

Induction was started with midazolam which was used for anxiolysis and amnesia and was administered 8 minute before intubation, by considering its time to peak effect between 3 to 5 min; then after 1 min study drug Fentanyl was given, its time of administration before intubation was 7 min (Peak effect in 5-6 minutes), then it was followed by lignocaine which was used for cough suppression and given 2 min before intubation and at last propofol was administered 30 sec prior to intubation.

Intubating conditions were assessed according to the criteria of Mark Scheller et al.[1] The ease with which ventilation via mask could be performed with no difference between the groups. None of the patient ventilation via mask was judged to be impossible. No patients appeared to manifest signs of opioid induced rigidity at any time. Intubating conditions like jaw mobility, exposure of vocal cords, position of vocal cords and response to intubation was significantly better in group II (fentanyl 3mcg/kg).

Jaw was completely mobile in $94 \%$ of patients in group II compared to $80 \%$ in group I. Vocal cords were completely visible in $92 \%$ of patients in group II compared to $74 \%$ in group I. Vocal cords were open in $92 \%$ of patients in group II compared to $69.38 \%$ in group I. Cough and movements after intubation was completely blunted in $82 \%$ of patients in group II compared to $46.80 \%$ in group I.

The findings of our study are almost consistent with study done by De Fatima et al.[2] They concluded that propofol $(3.0 \mathrm{mg} / \mathrm{kg})$ preceded by fentanyl $(3 \mathrm{mcg} / \mathrm{kg}$ ) provided adequate tracheal intubating conditions without significant haemodynamic changes. However we used propofol in the dosage of $2 \mathrm{mg} / \mathrm{kg}$.

Tsuda et al.[3] found that low dose fentanyl in the presence of propofol provided poor intubating conditions, however, increasing the dosages of fentanyl ( $3 \& 4 \mu \mathrm{gm} \mathrm{kg}-1$ ) provided good intubating conditions and our study is also consistent with the above findings. 
The study done by Monika Kohli et al[4] showed that intubation with propofol $(3 \mathrm{mg} / \mathrm{kg})$ and fentanyl $(4 \mathrm{mcg} / \mathrm{kg})$ provides better intubating conditions by avoiding side effects associated in intubation with propofol $(3 \mathrm{mg} / \mathrm{kg})$ and succinylcholine $(1 \mathrm{mg} / \mathrm{kg})$.

In our study, group II (Fentanyl $3 \mathrm{mcg} / \mathrm{kg}$ ) is effective in blunting the increase in pulse rate after intubation, when compared to group I. (Fentanyl $2 \mathrm{mcg} / \mathrm{kg}$ ). Even though the B.P is not altered significantly after intubation in group I (Fentanyl $2 \mathrm{mcg} / \mathrm{kg}$ ), the rise in B.P is completely blunted by group II (Fentanyl $3 \mathrm{mcg} / \mathrm{kg}$ ) after intubation along with Midazolam, Lignocaine and Propofol co induction and without neuromuscular blocking drugs.

The study done by Randal C. Cork et al[5] who compared the hemodynamic stress response with or without fentanyl preloading in rapid sequence induction protocol, and concluded that low dose fentanyl reduces same aspects of stress response to rapid sequence induction of anesthesia.

The study done by Masayasu Nakayama et al[6] showed that propofol administration 20 $\mathrm{mg} / \mathrm{kg} / \mathrm{hr}$ for 10 minutes is suitable in suppressive arousal reactions to tracheal intubation, but the addition of fentanyl is required to blunt the hemodynamic responses.

The study done by Tahira Hakeem Shah et al[7] showed the intubation with fentanyl and propofol has the advantage of less hemodynamic responses to endotracheal intubation.

Adding midazolam to propofol fentanyl co-induction was helpful in achieving better intubating conditions.[8] In our study fentanyl was administered 6 min prior to intubation provides better intubating condition and blunts hemodynamic response to intubation.[9,10,11]

Fentanyl and propofol combination provides better intubating conditions,[12] and hemodynamic stability when compared to fentanyl and thiopentone.[13]

In our study we used lignocaine in $1.5 \mathrm{mg} / \mathrm{kg}$ dose, 2 min prior to intubation which was adequate to suppress cough reflex to intubation.[14,15]

So finally we conclude with this prospective randomized double blind study done by us that, propofol, midazolam, lignocaine co-induction with $3 \mathrm{mcg} / \mathrm{kg}$ Fentanyl is a safe and effective method for intubation in selected patients and this combination represents a useful alternative technique for tracheal intubation when neuromuscular blocking drugs are contraindicated or should be avoided.

\section{REFERENCES:}

1. Mark S. Scheller, Mark H Zornow, Lawrence J saidman. Tracheal intubation without the use of muscle relaxants: A technique using propofol and varying doses of Alfentanil. Anaesth Analg 1992; 75: 788-93.

2. De Fatima, De Assuncao, Braga A, Da silva Braga FS, Poterio GM, Filier PR, Cremonesi E. The effect of different doses of propofol an tracheal intubating conditions without muscle relaxant in children. Eur J Anaesth 2001: 18 (6): 384-8.

3. Tsuda A, Yasumoto S, Akatawa T, Nakahara T. Tracheal intubation without muscle relaxants using propofol and varying doses of fentanyl, masui 2001; 50 (10): 1129-32.

4. Monica Kohli, Haider Abbas, comparison of intubating conditions following propofol and succinylcholine with propofol and fentanyl. J. Anaesth. Clinical Pharmacology 2008; 24(2), pg. 205-209.

5. Randal C Cork, Juli L weiss, stuart R hameroff, John Bentley. Fentanyl preloading for rapid sequence induction of anaesthesia. Anaesth Analg 1984; 63: 60-4. 


\section{ORIGINAL ARTICLE}

6. Masayasu Nakayama MD, Hiromichi ichinase MD, The effect of fentanyl on hemodynamic and bispectal index changes during induction of anaesthesia with propofol. Journal of clinical anaesthesia vol. 14, issue 2, March 2002 pg. 146-149.

7. Tahira Hakeem Shah, Tracheal intubation without neuromuscular block in children, Journal of PMI 2004; Vol. 18 pg. 117-123.

8. S. Prakash, D Arora, A combination of fentanyl-midazolam-propofol provides better intubating conditions than fentanyl-lignocaine-propofol in the absence of neuromuscular blocking agent. Acta Anaesthesiologica Scandinavia Aug. 2006 Vol. 50 issue 8, pg. 999 - 1004.

9. KO SH, Kim Dc, than YJ, Song HS., small dose fentanyl; optimal time of injection for blunting the circulatory responses to tracheal intubation: Anesth Analg 1998: 86: 658-661.

10. Safiya I Shaikh and Vijayalaxmi P Bellagali Tracheal intubation without neuromuscular block in children Indian J Anaesth. 2010 Jan-Feb; 54(1): 29-34.

11. Dahlgren $\mathrm{N}$ and messeter K. Treatment of stress response to laryngoscopy and intubation with fentanyl Anaesthesia 1981; 36: 1022-1026.

12. Striebel HW, Holzl M, Rieger A, Brummer G. Endotracheal intubation with propofol and fentanyl Anaesthetist. 1995 Dec; 44(12): 809-17.

13. K. Mc KEATING, I. M. BALI, J. W. DUNDEE The effects of thiopentone and propofol on upper airway integrity Anaesthesia Volume 43, Issue 8, pages 638-640, August 1988.

14. Yukioka H, Yoshimoto N, Nishimura K, Fujimori M. Intravenous lidocaine as a suppressant of coughing during tracheal intubation. Anesth Analg 1985; 64(12): 1189-92.

15. Stanley Tam, Rances Chung, Michael Campbell, They studied the Optimal Time of Injection of IV Lidocaine before Tracheal Intubation Anesth Analg 1987; 66: 1036-8.

\section{AUTHORS:}

1. Bhanuprakash S.

2. Sudhir Kumar P.

3. Sahajananda $\mathrm{H}$.

4. Sowmya M. J.

5. Venkatesh Murthy K. T.

\section{PARTICULARS OF CONTRIBUTORS:}

1. Assistant Professor, Department of Anaesthesia, Rajarajeshwari Medical College, Bangalore.

2. Senior Resident, Department of Anaesthesia, Rajarajeshwari Medical College, Bangalore.

3. Professor, Department of Anaesthesia, Rajarajeshwari Medical College, Bangalore.

FINANCIAL OR OTHER COMPETING INTERESTS: None
4. Assistant Professor, Department of Anaesthesia, Rajarajeshwari Medical College, Bangalore.

5. Professor, Department of Anaesthesia, Rajarajeshwari Medical College, Bangalore.

\section{NAME ADDRESS EMAIL ID OF THE CORRESPONDING AUTHOR:}

Dr. Bhanuprakash S, Assistant Professor, Department of Anaesthesia, Rajarajeshwari Medical College, Mysore Road, Kambipura, Bangalore.

E-mail: bhanushimoga@gmail.com

Date of Submission: 25/06/2015.

Date of Peer Review: 26/06/2015.

Date of Acceptance: 13/07/2015.

Date of Publishing: 17/07/2015. 